\title{
Research on Risk Assessment of Supply Chain Financing for Big Data Enterprises
}

\author{
Jian $\mathrm{He}^{\mathrm{a}} \quad$ Hongmei Zhang ${ }^{\mathrm{b}}$ \\ School of Big Data Application and Economics, Guizhou University of Finance and Economics, Guiyang Guizhou 550025, China \\ adhwgd264nc@qq.com, bhm1035@qq.com

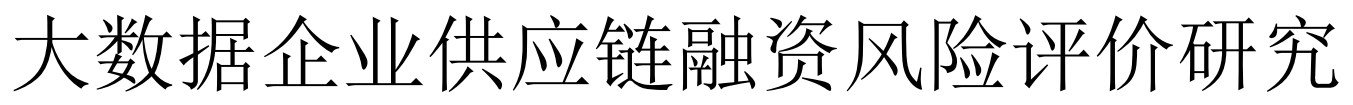 \\ 贺健 ${ }^{\mathrm{a}}$ 张红梅 $^{\mathrm{b}}$ \\ 贵州财经大学大数据应用与经济学院, 花溪, 贵阳, 贵州, 550025, 中国 \\ adhwgd264nc@qq.com, bhm1035@qq.com
}

\begin{abstract}
Under the background of current enterprise financing difficulties, the development of supply chain finance has become one of the important options for enterprise financing. Based on principal component analysis and logistic regression model analysis, this paper chooses evaluation indexes from profitability and growth ability, and establishes a supply chain default risk early warning model for large data enterprises. Empirical results show that its early warning accuracy is high, which provides a new idea for the early warning research of supply chain financing risk for large data enterprises.
\end{abstract}

Keywords- Supply Chain Finance, Big Data Enterprises, Financing risk

摘要一在当前企业融资难的背景下, 发展供应链金融这种融 资模式成为企业融资的重要选择之一。本文以大数据企业为研 究对象, 基于主成分分析法和 logistic 回归模型分析, 从盈利 能力和成长能力等方面选取评价指标, 建立了大数据企业供应 链违约风险预警模型。实证表明其预警准确率较高, 这为大数 据企业供应链融资风险预警研究提供了新思路。

关键词一供应链金融; 大数据企业; 融资风险

\section{I. 引言}

近些年来, 随着企业供应链管理的不断发展, 有关于 供应链资金流的管理正在被越来越管理者所重视, 这其中 核心的融资问题最为企业经营者所关注。供应链融资从最 早的仓储质押融资和货物抵押贷款发展到后来的保理业 务, 最后逐渐过渡到物流金融。供应链融资的主要方式仍
是银行等金融机构为供应链中的企业提供贷款业务, 在这 一融资过程中, 银行为了防范并且控制融资风险, 对企业 的合理授信成为最为关键的环节。供应链融资作为一种新 型的金融产品正在越来越受到企业和社会的关注, 这一融 资渠道也正在被越来越多的企业所采纳。同时，随着人类 产生的数据量成几何式地增加, 大数据一词正在被越来越 多地被提及，有关于大数据的构思和概念在不断地提出、 完善, 并在实际中被普遍运用, 由此催生出了一大批与大 数据直接相关或紧密相关的企业, 我们称其为大数据企业。 如华为、小米、腾讯等大企业都准备建立基于 “大数据” 的企业生态系统。但是目前总体来说对于大数据企业的界 定还很模糊, 只有部分券商和少量学者对这一概念做出过 粗略的划分。如安信证券指出, 遵循自身拥有大数据和为 客户提供大数据分析运营两条主线选出的企业即为大数 据企业。周永祥(2013)[1]将大数据企业, 划分为数据存储 和处理、数据运营维护两个类别。然而基于这些学者的研 究, 只有很少的企业符合大数据企业的标准, 本文认为大 数据企业的范围应该进一步扩大, 并将主营业务、核心能 力和未来发展战略与大数据紧密相关的企业定义为大数 据企业。

对于正处在经济转型时期的中国, 如何抓住大数据的 发展契机, 实现经济高质量发展, 成为需要迫切解决的问 题。这些由大数据衍生出来的新兴产业和企业正在逐渐成 为我国经济的新动力, 对我国未来经济发展有重要影响。 目前国内少有学者研究大数据企业的供应链融资风险, 因 此为了确保大数据企业平稳健康发展, 充分发挥数字资源 的战略作用, 结合当前供应链金融模式, 对大数据企业进 行供应链融资风险评价研究就显得尤为必要。 


\section{II. 文献回顾}

国外学者从不同的角度对供应链融资模式进行了研 究。Killen 联合公司基于金融供应链解决方案提出了四个 方面: 基于企业软件的解决方案、实务供应链的解决方案、 金融供应链点解决方案、贯穿金融供应链解决方案。

Santomero(2000)[2] 认为随着金融中介的不断成熟, 供应链 与金融中介之间的合作将给金融业带来质的飞跃。

Sadlovska 和 Enslow(2006)[3]提出供应链融资是企业改善 金融指标创造成本优势的新机遇, 其中对于供应链融资模 式运行过程中出现的一些问题, Sadlovska(2007a)[4]认为 企业应该从融资、技术以及可视性等方面提高供应链金融 的整体竞争力, 同时在另一篇文献中 Sadlovska(2007b)[5] 指出供应链融资缺乏最佳行为规范知识, 应该用应收账款 周转天数、应付账款周转天数等来区别衡量企业的供应链 金融业务水平。Dean Kashiwagi(2017)[6]通过一种新的风 险管理模型发现供应链交易中主要风险源在买方或融资 方。Matoussi(2010)[7]曾采用 logit 模型和 BP 神经网络模 型来评估研究供应链融资信用风险, Blome 和 Schoenherr(2016)[8]指出供应链融资风险管理已经成为金 融危机的主要因素, 通过交易成本理论, 得出企业能够通 过转移自身风险的方式来有效的控制风险。

国内学者也对供应链融资进行了相关研究, 如张敬峰 (2013)[9]指出产业共生关系不仅对供应链金融提出了需 求, 同时也为供应链金融运作和发展奠定了基础, 两者是 相互依存的。石汉祥(2003)[10]认为由于银行和企业之间 还不存在一个成熟的、彼此信赖的商业模式, 所以建立供 应链融资风险评价体系有利于银行合理有效的管理风险 以及正确的评估企业, 这对于整个供应链的合理运转有着 重要意义。冯㵭、吴崇(2012)[11]认为商业银行在提供供 应链融资业务时, 可以根据风险产生的客观原因, 把风险 来源分成两个部分, 一是由于参与者本身经营操作或是信 息不对称等原因而引发的风险, 另外则是由于外部环境政 策等所引发的风险, 并通过对两类风险进行分类选取, 最 后综合得出评价体系。在供应链融资风险评价研究的实证 方面, 刘艳春(2016)[12]选取了财务指标和非财务指标, 采用 SEM 和灰色关联法来研究企业供应链融资的违约风 险。蒋曼曼 (2017)[13] 则是采用 logistic 回归模型来研究 分析 61 家上市公司的违约风险。

综上所述, 在供应链融资风险分析方面, 国外研究起 步较早, 而国内还没有形成一个成熟的体系, 并且大部分 学者都是以中小企业为研究对象, 很少有学者选取大数据 企业为研究对象来进行供应链融资风险评价。相比于传统 企业, 大数据企业更加偏向于让数据说话, 大数据企业可
以实现对各种财务数据以及相关数据的高效整理和定期 分析, 将企业在运营过程中存在的问题进行及时处理, 最 大程度地降低企业财务风险, 所得到的数据也更加地全面, 准确和有效。因此在现有的参考文献上, 以大数据企业为 研究对象, 充分考虑反应企业综合情况的必要指标以及与 大数据企业盈利、成长能力方面等相关指标, 初步得到指 标评价体系, 然后采用主成分分析法来构建指标评价体系, 并在此基础上利用 logistic 模型来对大数据企业供应链融 资风险评估模型进行分析。

\section{III. 大数据企业供应链融资违约风险评估}

从本质上讲，供应链融资仍然是银行或其他金融机构 向企业提供贷款的业务，这一过程当中会受到交易双方信 息不对称的影响而存在违约风险。违约风险是供应链融资 中面临的首要风险, 所以对违约风险的正确评估是风险管 理的重中之重。违约风险指的是企业(借款人) 因经营不善 或其他原因造成无力偿还或者不愿偿还银行等金融机构 的贷款, 从而使得银行遭受损失的可能性。本文将构建供 应链融资模式下的信用评价指标体系, 运用 logistic 回归 模型对其违约概率进行评估, 以期综合反映供应链融资中 大数据企业的信用情况。

\section{1 样本选取及初始财务指标选取}

Logistic 回归分析通过最大似然估计法来估计参数, 无需太多假设前提, 所需参数也较少, 因此本文选用该模 型进行分析。Logistic 回归模型函数为:

$$
\mathrm{P}=\frac{1}{1+e^{-z}}
$$

其中 $Z=\beta_{0}+\beta_{1} X_{1}+\ldots+\beta_{n} X_{n}, \beta 0$ 表示常量, $\beta_{n}$ 表示对 应的回归系数。 $X_{n}$ 代表各指标变量。因变量 $\mathrm{P}$ 表示企业 出现违约的概率, $\mathrm{P}$ 越接近 0 表示企业违约风险越低, $\mathrm{P}$ 越接近于 1 表示企业违约风险越高。

参考以往的文献发现, 大多数学者都是以某一区域或 某一个行业的企业作为研究对象, 鲜有学者以大数据企业 为研究对象的融资风险评价。考虑到数据的可获得性, 本 文从沪深两个证券交易所的上市企业中，按照前文所述的 大数据企业定义标准, 选取了我国 2018 年 135 家符合要 求的上市大数据企业来进行研究, 其中包括 35 家财务状 况出现问题即 ST 企业和 100 家财务状况正常的非 ST 企 业。当一个公司连续两年亏损或者净资产低于股票面值的 时候, 证监会就会在其股票名称前就会加上 “ST”。一般 来说被 ST 的企业往往都是因为财务问题等原因而被特殊 处理, 因此这类企业往往违约概率较大, 在本文中被视作 违约企业。 
大数据企业作为技术密集型企业的典型代表企业, 具 有研发投入高, 成长速度快和盈利能力强等特点, 因此在 评价指标的选取上, 既要考虑能够综合反应企业整体情况 的必要指标, 又要考虑与大数据企业成长能力和盈利能力 相关的指标。因此本文基于大数据企业和供应链融资自身 特点, 参考张铁山[14]等人对大数据企业研究指标体系构 建, 最终选取了净资产收益率、资产报酬率、流动比率、 速度比率、每股收益增长率、营业收入增长率、营业利润 增长率、总资产增长率、应收账款周转率、流动资产周转 率、固定资产周转率、资产负债率、销售现金比率和销售 商品劳务收入现金/营业收入等 14 个指标作为因子来研究 供应链融资风险。本文的指标数据主要来源于 RESSET 金 融研究数据库。

\section{2 logistic 模型建立}

\section{2 .1 主成分分析}

运用 spss23 软件对 135 家企业数据进行主成分分析, 提取主成份因子。为了消除观测量纲和数量级差异的影响, 对样本观测数据进行了标准化处理。

\section{(1) 样本数据处理与检验}

如表 1 所示样本数据不存在数据缺失的情况, 有效样 本数量为 135 个, 通过标准化处理后的数据有利于提高回 归分析的准确性。然后用 KMO 和 Bartlett 法对指标体系 进行检验, 结果如表 2 所示。一般来说, KMO 值大于 0.6 时, 数据是比较适合做主成分分析的, 当 $\mathrm{KMO}$ 值小于 0.5 , 数据就不适合做主成分分析。表 2 中显示的 KMO 值为 0.632 , 大于 0.6 , 显着性水平小于 0.5 , 表明该数据适合 做主成分分析。

\section{（2）公因子解释程度分析}

由表 3 可以看出大部分指标的被解释程度都比较高, 只有总资产增长率和应收账款周转率损失信息较多, 但不 影响本文建立模型的质量。

\section{(3) 主成分因子提取}

为了降低所选 14 个评价指标的多重相关性, 本文采 用主成分分析法。碎石图是反映各个因子的重要程度, 因 子越重要, 特征值越大, 直线越陡峭。所得碎石图如图 1 所示。由图 1 可知, 前 5 个指标的特征值均大于 1 , 依据 总方差及旋转后的成份矩阵(表 4)综合计算分析, 选取前 5 个主成分因子分别定义为 FAC1,FAC2,FAC3,FAC4,FAC5, 且由表 5 可知, 这 5 个主成分因子解释了总方差的 73.32
$6 \%$, 解释程度较高, 通过表 5 可知, 这 5 个主成分因子 基本包含了所有指标信息。

表1 描述统计

\begin{tabular}{|c|c|c|}
\hline & 平均值 & 标准偏差 \\
\hline 净资产收益率 & -6.553359 & 52.5885365 \\
\hline 资产报酬率 & 1.036881 & 17.7055964 \\
\hline 流动比率 & 2.867828 & 3.0028751 \\
\hline 速动比率 & 2.593873 & 2.9543206 \\
\hline 每股收益增长率 & -305.474869 & 1177.9709403 \\
\hline 营业收入增长率 & 33.436169 & 98.2286267 \\
\hline 营业利润增长率 & -180.781107 & 1484.6443262 \\
\hline 总资产增长率 & 13.183700 & 39.7223214 \\
\hline 应收账款周转率 & 10.169490 & 31.0994197 \\
\hline 流动资产周转率 & .962761 & .8213819 \\
\hline 固定资产周转率 & 128.655351 & 618.4046491 \\
\hline $\begin{array}{c}\text { 销售商品劳务收入现金/ } \\
\text { 营业收入 }\end{array}$ & 103.461187 & 28.3698213 \\
\hline 销售现金比率 & -.454648 & 73.4050356 \\
\hline 资产负债率 & 41.376645 & 23.5756543 \\
\hline
\end{tabular}

表2 KMO和Bartlett检验

\begin{tabular}{|c|c|c|}
\hline \multirow{2}{*}{ KMO取样适切性量数 } & 0.632 \\
\hline \multirow{2}{*}{$\begin{array}{c}\text { 巴特利特球 } \\
\text { 形度检验 }\end{array}$} & 近似卡方 & 1283.217 \\
\cline { 2 - 3 } & 自由度 & 91 \\
\cline { 2 - 3 } & 显著性 & 0.000 \\
\hline
\end{tabular}

这 5 个因子分别定义为: FAC1 主要表示了净资产收 益率、资产报酬率和资产负债率等指标, 主要代表企业的 盈利能力。 FAC2 主要表达了流动比率、速动比率, 反 映了企业的偿债能力。FAC3 主要表达了固定资产周转率、 流动资产周转率和营业收入增长率, 主要代表了企业的营 运能力。FAC4 主要表达了营业利润增长率、每股收益增 长率等指标, 代表了企业的成长能力,FAC5 主要表达了销 售现金比率和销售商品劳务收入现金/营业收入等指标, 代表了企业的现金获取能力。 
表3 公因子方差

\begin{tabular}{|c|c|c|}
\hline & 初始 & 提取 \\
\hline 净资产收益率 & 1.000 & 0.895 \\
\hline 资产报酬率 & 1.000 & 0.851 \\
\hline 流动比率 & 1.000 & 0.965 \\
\hline 速动比率 & 1.000 & 0.966 \\
\hline 每股收益增长率 & 1.000 & 0.796 \\
\hline 营业收入增长率 & 1.000 & 0.694 \\
\hline 营业利润增长率 & 1.000 & 0.646 \\
\hline 总资产增长率 & 1.000 & 0.467 \\
\hline 应收账款周转率 & 1.000 & 0.522 \\
\hline 流动资产周转率 & 1.000 & 0.591 \\
\hline 固定资产周转率 & 1.000 & 0.698 \\
\hline 销售商品劳务收入现金/营业收入 & 1.000 & 0.793 \\
\hline 销售现金比率 & 1.000 & 0.600 \\
\hline 资产负债率 & 1.000 & 0.777 \\
\hline
\end{tabular}

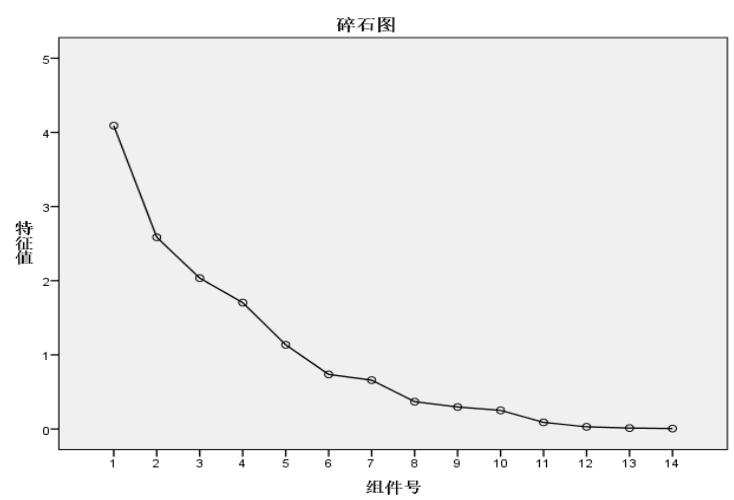

图 1 碎石图

按照表6成分得分系数矩阵, 通过公式 $\mathrm{FAC}_{\mathrm{i}}=\sum C_{i j}$ 得 出各因子表达式为:

$F A C 1=0.344 X_{1}+0.346 X_{2}-0.082 X_{3}-0.076 X_{4}+0.032 X_{5}+$ $0.089 X_{6}-0.092 X_{7}+0.151 X_{8}+0.143 X_{9}-0.145 X_{10}-$ $0.089 X_{11}+0.141 X_{12}+0.074 X_{13}-0.288 X_{14}$

(1)
表4 旋转后的成分矩阵

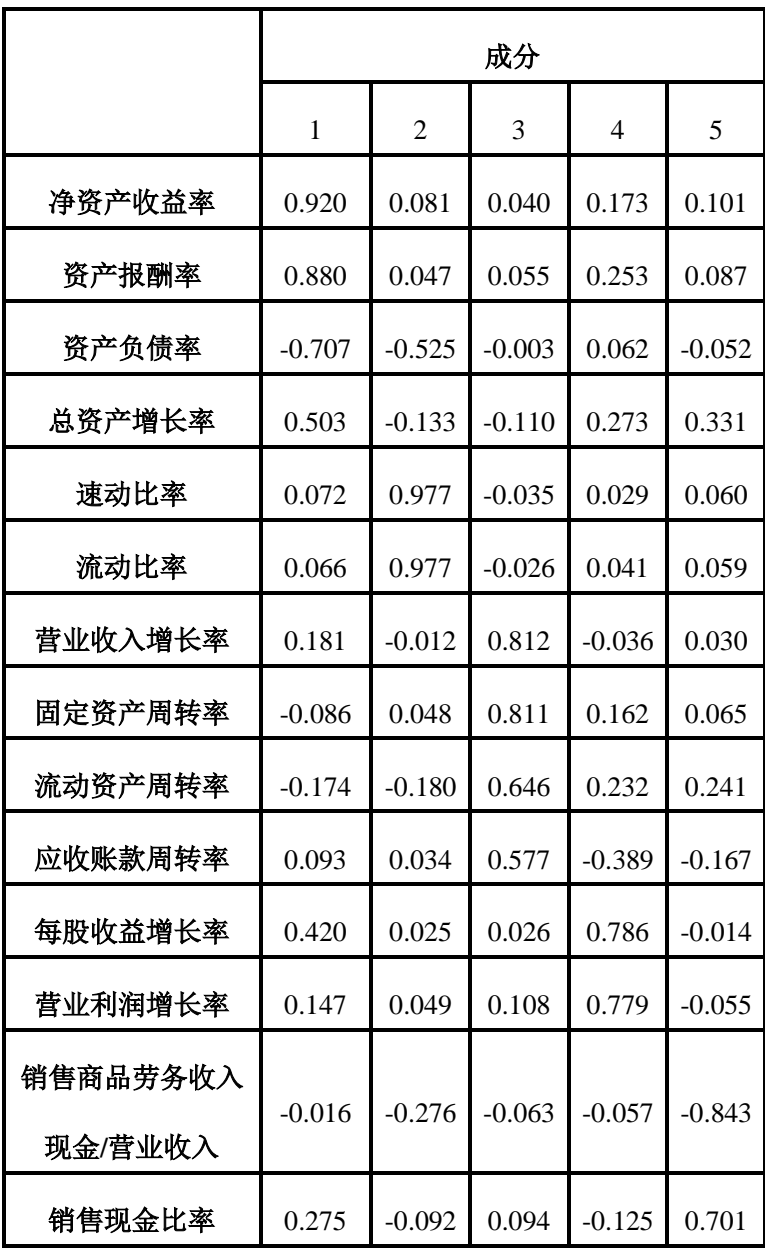

表5 总方差解释

\begin{tabular}{|c|c|c|c|c|}
\hline \multirow{2}{*}{ 成 } & \multicolumn{2}{|c|}{$\begin{array}{c}\text { 初试特征值 } \\
\text { 分 }\end{array}$} & $\begin{array}{c}\text { 方差百分 } \\
\text { 比 }\end{array}$ & 旋转载荷平方比 \\
\hline 1 & 25.731 & 25.731 & $\begin{array}{c}\text { 方差百 } \\
\text { 分比 }\end{array}$ & 累计\% \\
\hline 2 & 16.258 & 41.989 & 16.545 & 19.545 \\
\hline 3 & 14.069 & 56.058 & 15.073 & 36.228 \\
\hline 4 & 9.196 & 65.253 & 11.796 & 63.096 \\
\hline 5 & 8.072 & 73.326 & 10.230 & 73.326 \\
\hline
\end{tabular}

\subsection{2 logistic模型函数}

将上述提取的 5 个主成分因子作为协变量, 企业违约 概率为因变量, 由于企业只会出现违约和不违约两种情 况, logistic模型的基本原理就是把因变量分为对立的两个 结果, 即在本文中的违约或不违约, 故本文采用logistic 回 归模型进行实证分析, 并将被 ST的企业定义为“1”, 非ST 企业定义为“0”。利用SPSS进行二元logistic回归分析, 
表6 成分得分系数矩阵

\begin{tabular}{|c|c|c|c|c|c|}
\hline & \multicolumn{5}{|c|}{ 成分 } \\
\hline & 1 & 2 & 3 & 4 & 5 \\
\hline $\begin{array}{c}\text { 净资产收益 } \\
\text { 率 } \mathbf{X}_{1}\end{array}$ & 0.377 & -0.052 & 0.008 & -0.070 & -0.050 \\
\hline $\begin{array}{c}\text { 资产报酬率 } \\
\mathbf{X}_{2}\end{array}$ & 0.346 & -0.060 & 0.013 & -0.006 & -0.055 \\
\hline 流动比率 $\mathbf{X}_{3}$ & -0.082 & 0.438 & 0.009 & 0.047 & -0.007 \\
\hline 速动比率 $\mathbf{X}_{4}$ & -0.076 & 0.437 & 0.004 & 0.038 & -0.006 \\
\hline $\begin{array}{c}\text { 每股收益增 } \\
\text { 长率 } \mathbf{X}_{5}\end{array}$ & 0.032 & -0.003 & -0.007 & 0.469 & -0.075 \\
\hline $\begin{array}{c}\text { 营业收入增 } \\
\text { 长率 } \mathbf{X}_{6}\end{array}$ & 0.089 & -0.004 & 0.391 & -0.085 & -0.060 \\
\hline $\begin{array}{c}\text { 营业利润增 } \\
\text { 长率 } \mathbf{X}_{7}\end{array}$ & -0.092 & 0.039 & 0.038 & 0.520 & -0.078 \\
\hline $\begin{array}{c}\text { 总资产增长 } \\
\text { 率 } \mathbf{X}_{8} \\
\end{array}$ & 0.151 & -0.120 & -0.089 & 0.083 & 0.200 \\
\hline $\begin{array}{c}\text { 应收账款周 } \\
\text { 转率 } \mathbf{X}_{9}\end{array}$ & 0.143 & 0.017 & 0.303 & -0.307 & -0.181 \\
\hline $\begin{array}{c}\text { 流动资产周 } \\
\text { 转率 } \mathbf{X}_{\mathbf{1 0}}\end{array}$ & -0.145 & -0.051 & 0.284 & 0.176 & 0.165 \\
\hline
\end{tabular}

假设分界点 $\mathrm{P}=0.5$, 若 $\mathrm{P}$ 大于 0.5 , 则认为企业违约风险较 大, 若 $\mathrm{P}$ 小于 0.5 , 则认为企业不存在违约风险。根据表 7 建立logistic回归模型, 其中

$P$

$=\frac{1}{1+\mathrm{e}^{-(1.063+2.246 \mathrm{FAC} 1-0.21 \mathrm{FAC} 2-1.593 \mathrm{FAC} 3+1.276 \mathrm{FAC} 4+0.808 \mathrm{FAC} 5)}}$

\subsection{3 模型预测正确率}

任何模型检验都会出现两种情况：第一类错误率和 第二类错误率。一种是模型拒绝了实际上成立的、正确 的假设, 另一种则是接受了错误的假设。在本文中, 将 第一类错误率定义为把存在违约情况的企业误判成不存 在违约情况的企业, 第二类错误率为把不存在违约情况 的企业误判成存在违约情况的企业, 通常第一类错误率 所带来的损失往往会大于第二类错误率。模型预测检验 结果如表8所示。

\begin{tabular}{|c|c|c|c|c|c|}
\hline & B & $\begin{array}{l}\text { 标准 } \\
\text { 误差 }\end{array}$ & 瓦尔德 & $\begin{array}{c}\text { 显著 } \\
\text { 性 }\end{array}$ & $\operatorname{Exp}(B)$ \\
\hline FAC1 & 2.246 & 0.547 & 16.837 & 0.000 & 9.451 \\
\hline FAC2 & -.210 & 0.237 & 0.785 & 0.376 & 0.811 \\
\hline FAC3 & -1.593 & 0.593 & 7.211 & 0.007 & 0.203 \\
\hline FAC4 & 1.276 & 0 & 2.583 & 0.108 & 3.583 \\
\hline FAC5 & 0.808 & 0.517 & 2.443 & 0.000 & 2.244 \\
\hline 常量 & 1.063 & 0.305 & 12.139 & 0.000 & 2.896 \\
\hline
\end{tabular}

\begin{tabular}{|c|c|c|c|c|c|}
\hline & \multirow[b]{2}{*}{ 实测 } & & \multicolumn{3}{|c|}{ 预测 } \\
\hline & & & \multicolumn{2}{|c|}{ 违约 } & 正确百分比 \\
\hline \multirow{3}{*}{ 步骤 1} & \multirow{2}{*}{ 违约 } & 1 & 21 & 14 & 60.0 \\
\hline & & 0 & 2 & 98 & 98.0 \\
\hline & \multicolumn{2}{|c|}{ 总体百分比 } & \multicolumn{3}{|c|}{88.1} \\
\hline
\end{tabular}

由表 8 可知, 本文 logistic 回归模型的总体预测准确 率达到了 $88.1 \%$, 其中 ST 企业被正确预测的概率为 $60 \%$, 第一类错误率为 $40 \%$, 非 ST 企业被正确预测的概率为 $98 \%$, 第二类错误率为 $2 \%$ 。该模型对 ST 企业预测的准确 率较低, 这可能跟 ST 公司的样本量较少有关, 另外也可 能跟现实生活中的 ST 企业并不一定都存在违约情况有关。

从以上分析中可以看出, 大体来说 logistic 模型在评 价大数据企业供应链融资违约风险上准确度较高, 具有一 定的操作性和可行性。

\section{IV. 结论}

本文以沪深两市 $\mathrm{A}$ 股上市公司的 135 家大数据企业为 样本进行实证研究, 通过企业的盈利能力和成长能力等方 面选取了 14 个评价指标, 通过主成分分析得到了五个主 成分因子, 并基于 logistic 模型构建大数据企业供应链融 资风险评估模型, 实证结论如下。

(1)为了降低指标之间的多重相关性, 本文通过主成 分分析法将 14 个指标分成 5 个主因子, 并把 5 个主成分 因子作为协变量, 而不是传统地将某些单个指标作为协变 量, 企业违约概率作为因变量, 结果表明 logistic 模型在 评价供应链融资的违约风险上具有可行性。 
(2)实证过程中将 14 个指标进行整合得到 5 个主成分 因子，从而得到企业的违约概率公式(2),这表明大数据企 业的成长能力和盈利能力等是供应链融资业务中违约风 险的关注要点。

(3)该模型总体预测准确度较高, 达到了 $88.1 \%$, 这为 大数据企业供应链融资风险评价提供了较好的参考模型。 其中第一类错误率为 $40 \%$ ，第二类错误率为 $2 \%$ ，第一类 错误率高于第二类错误率, 这可能跟 ST 公司样本量较少 有关, 但是总体来说目前我国的大数据企业信用风险状态 较为良好。

\section{致谢}

本研究得到国家自然科学基金地区项目《贷款风险补 偿资金对科技型中小企业信贷配给的影响机理研究》

(71263011)、《基于文本信息的科技型中小企业信用风险 识别机理研究》(71861003)的大力资助。

$$
\text { 参考文献 }
$$

[1] 周 永祥. 关注大数据 概念股. 股市动态分 析,pp.21-28,2013.

[2]Santomero,A.M. and Seater,J.J, Is there an Optimal Size for the Financial Sector?.Journal of Banking and Finance,vol.24,issue6,pp.944-965,2000

[3]Sadlovska,V. and Enslow B,2006.New Strategies for Finanzial Supply Chain Optimization:Rethinking Financial Practices with Your Suppliers to Maximize Bottom Line Performance. Aberdeen Group.

[4]Sadlovska,V.2007a. Technology Platforms for Supply Chain Finance: How to Drive Competitive Business Advantage by Increasing Payment and Financing Automation with Business Parthers . 2007.03.

[5]Sadlovska,V. 2007b. The 2008 State of Market in Supply Chain Finance. 2007.12.

[6]Dean Kashiwagi, Jacob Kashiwagi,“A New Risk Management Model,"Journal of Risk Analysis and Crisis Response,vol.2,issue4,pp.233-251,2017.

[7]Matoussi,H., and Krichène,A., Credit Risk Evaluation of a Tunisian Commercial Bank: Logistic Regression Versus Neural Network Modelling. Journal of Accounting and Management Information Systems,vol.9,issue 1,pp.92-119,2010.

[8]Blome,C.,and Schoenherr,T.,Supply Chain Risk Management in Financial Crises-A Multiple Case-study
Approach.International Journal of Production Economics,vol.134,issue 1,pp.43-57,2011.

[9]张敬峰.产业共生金融生态与供应链金融.金融论 坛.vol.18,issue 8,pp.69-74,2013.

[10]石汉祥,论国有商业银行的信贷风险管理.武汉大学学 报(社会科学版), issue 1,pp.77-81,2003.

[11]冯懃、吴崇. 国内商业银行供应链融资业务操作风险分 析与度量方法选择. 现代物业, vol.111issue 7,pp.60-63,2012.

[12]刘艳春,崔永生.供应链金融下中小企业信用风险评价 -基于 SEM 和灰色关联度模型.技术经济与管理研究, issue12,pp.14-19,2016.

[13]蒋曼曼.供应链金融视角下企业信用风险评价研究.经 济与管理,issue 2,pp.140-142,2017.

[14]张铁山,邓新策.基于上市大数据企业的经营绩效与研 发投入关系研究.工业技术经济, vol.35,issue 9,pp.77-84,2016. 